\title{
Does autonomic neuropathy play a role in erythropoietin regulation in non-proteinuric Type 2 diabetic patients?
}

\author{
V. Spallone, M. R. Maiello, N. Kurukulasuriya, A. Barini*, M. Lovecchio†, R. Tartaglione†, \\ G. Mennunif and G. Menzinger
}

Department of Internal Medicine, Tor Vergata University, and *Institute of Biochemistry, Institute of Haematology and ¥Institute of Neurology,

Catholic University, Rome, Italy

Accepted 11 December 2003

\begin{abstract}
Aims Erythropoietin (EPO)-deficient anaemia has been described in Type 1 diabetic patients with both severe autonomic neuropathy (AN) and proteinuria. This study was aimed at distinguishing between the effects of AN and nephropathy on haemoglobin and EPO levels in Type 2 diabetic patients at an early stage of diabetic nephropathy.
\end{abstract}

Methods In 64 Type 2 diabetic patients (age $52 \pm 10$ years, duration $10 \pm 9$ years) without overt nephropathy and other causes of anaemia or EPO deficit, we assessed cardiovascular tests of AN, 24-h blood pressure (BP) monitoring, urinary albumin excretion rate (UAE), a full blood count, and serum EPO.

Results Although the Type 2 diabetic patients with AN did not show differences in haemoglobin and $\mathrm{EPO}$ when compared with patients without AN, the presence of haemoglobin $<13 \mathrm{~g} / \mathrm{dl}$ was associated with the presence of AN $\left(\chi^{2}=3.9, P<0.05\right)$ and of postural hypotension $\left(\chi^{2}=7.8, P<0.05\right)$. In a multiple regression analysis including as independent variables gender, body mass index, duration of diabetes, smoking, creatinine, 24-h UAE, 24-h diastolic BP, ferritin, erythrocyte sedimentation rate, and autonomic score, we found that the only variables independently related to haematocrit were autonomic score, ferritin and erythrocyte sedimentation rate. Finally, the physiological inverse relationship between EPO and haemoglobin present in a control group of 42 non-diabetic non-anaemic subjects was completely lost in Type 2 diabetic patients. The slopes of the regression lines between EPO and haemoglobin of the control subjects and the Type 2 diabetic patients were significantly different $(t=14.4, P<0.0001)$.

Conclusions This study documents an early abnormality of EPO regulation in Type 2 diabetes before clinical nephropathy and points to a contributory role of $\mathrm{AN}$ in EPO dysregulation.

Diabet. Med. 21, 1174-1180 (2004)

Keywords autonomic neuropathy, Type 2 diabetes, erythropoietin, kidney function, anaemia

Abbreviations EPO, erythropoietin; AN, autonomic neuropathy; BP, blood pressure; $\mathrm{Hb}$, haemoglobin; $\mathrm{Ht}$, haematocrit
Correspondence to: Vincenza Spallone PhD, Dipartimento di Medicina Interna, Università di Tor Vergata, via Montpellier 1, 00133 Roma, Italy.

E-mail: vispa@mclink.it

\section{Introduction}

Erythropoietin (EPO), the principal regulator of erythropoiesis [1], is produced by the peritubular fibroblast-like interstitial cells of the renal cortex in response to tissue hypoxia [2-4]. 
Typically, there is an inverse $\log$ /linear relationship between EPO levels and haemoglobin $(\mathrm{Hb})$ concentration or haematocrit (Ht) [1].

In addition to the known neural control of renal circulation and tubular function [5], experimental data also support a role for renal sympathetic innervation in the regulation of EPO production [6,7], although its clinical relevance is unclear [2]. Anaemia with a relative deficit of EPO has been observed in patients with dysautonomias [8-10] and in some Type 1 diabetic patients with both severe autonomic neuropathy (AN) and proteinuria [11-14]. However, at an advanced stage of diabetic nephropathy the common coexistence of AN makes it difficult to distinguish the respective roles of kidney damage and autonomic dysfunction in EPO deficit. Reports in this field in Type 2 diabetes are rare and inconclusive [15-18]. Moreover, in those studies the lack of any assessment of autonomic function and the inclusion of patients with advanced diabetic nephropathy or with subnormal creatinine clearance made any conclusions on the impact of autonomic dysfunction on EPO regulation impossible [15-18]. Furthermore, the substantial heterogeneity of the morphological lesions of diabetic nephropathy in Type 2 diabetes [19] makes a simple extrapolation of data from Type 1 to Type 2 diabetes unreliable.

Thus, this study was aimed at identifying the possible impact on $\mathrm{Hb}$ levels and on EPO regulation of autonomic dysfunction and nephropathy in Type 2 diabetic patients at an early stage of diabetic nephropathy, by excluding those with overt nephropathy and by accurate assessment of cardiac autonomic function.

\section{Patients and methods}

\section{Neurological assessment}

Autonomic function was assessed by four cardiovascular tests (deep breathing, lying to standing, Valsalva manoeuvre and postural hypotension) that were performed according to standard procedure [20] and evaluated using age-related reference values [21]. An autonomic score was obtained from the sum of scores given to each of the four tests ( 0 for a normal result, 1 for a borderline result, and 2 for an abnormal result) [21,22]. Type 2 diabetic patients were divided according to the autonomic tests results into two groups with $\mathrm{AN}$ (one or more abnormal tests) and without AN (less than one abnormal test).

\section{BP monitoring and urinary measurement}

Non-invasive 24-h ambulatory blood pressure (BP) monitoring (ABPM) was performed using an oscillometric recorder (SpaceLabs 90207, Redmond, WA, USA) [23]. The device was programmed to measure BP every $20 \mathrm{~min}$ for $24 \mathrm{~h}$. Systolic and diastolic BP measurements were averaged for the day and the night periods, according to the patients' reported time of waking up and going to bed. In addition, the percentage change from day to night in BP ( $\Delta$ day-night) was calculated as: (day $\mathrm{BP}-$ night $\mathrm{BP}) \times 100 /$ day $\mathrm{BP}$.
Albumin concentration was measured by a double antibody radioimmunoassay (Albumin RIA 100; Pharmacia AB, Uppsala, Sweden) on the timed day and overnight urine collections. Urinary albumin excretion (UAE) was calculated for the day and the night periods, and for the $24-\mathrm{h}$ period. In addition, the percentage change from day to night in UAE ( $\Delta$ day-night) was calculated.

\section{Evaluation of haematological parameters}

EPO levels were measured on morning serum samples by an enzyme-linked immunosorbent assay based on the doubleantibody sandwich method (Quantikine IVD Epo ELISA; R\&D Systems, Inc., Minneapolis, MN, USA). Serum EPO normal range was 3.3-16.6 mIU/ml. Full blood count, serum iron, ferritin, vitamin $\mathrm{B}_{12}$, folate concentrations, and thyroid hormones were also measured, these latter in order to exclude previously unknown causes of anaemia (iron or vitamin deficiency, hypothyroidism). Finally, serum creatinine and erythrocyte sedimentation rate (ESR) were measured.

Presence of non-proliferative or proliferative retinopathy was determined by ophthalmoscopic examination.

\section{Patients}

Sixty-four subjects with Type 2 diabetes were consecutively recruited at the diabetic clinic of the University of Rome 'Tor Vergata'. Inclusion criteria were age $<70$ years and a urinary albumin concentration on three early morning urine collections in the range of normo- or microalbuminuria $(0-200 \mathrm{mg} / \mathrm{l})$. Exclusion criteria were macroalbuminuria (urinary albumin concentration $>200 \mathrm{mg} / \mathrm{l}$ ), impaired renal function (serum creatinine $>115 \mu \mathrm{mol} / 1$ or creatinine clearance $<70 \mathrm{ml} \mathrm{min}^{-1}$ $1.73 \mathrm{~m}^{-2}$ ), urinary infection, significant abnormality of hepatic, haematopoietic, respiratory or endocrine function, known causes of anaemia or EPO deficit, chronic infectious disorders or active foot ulcers, cerebrovascular or coronary heart disease, arrhythmia, and any other condition or drug affecting autonomic nervous function other than hypertension or antihypertensive agents. The study was approved by the Ethics Committee of Tor Vergata University and informed consent was obtained from all participants.

Mean age was 52.1 years (range 26-68) and the mean duration of diabetes was 10.2 years (range $0.2-35$ ). Forty patients were men and 24 women. Mean body mass index (BMI) was $27.5 \mathrm{~kg} / \mathrm{m}^{2}$ (range 17.1-35.7). Seven patients (10.9\%) were treated with diet, $40(62.5 \%)$ with oral agents (sulphonylureas and/or metformin), seven with oral agents and insulin (10.9\%), and $10(15.6 \%)$ with insulin alone. Fifteen patients $(23.4 \%)$ had a diagnosis of hypertension according to the World Health Organization (casual BP $>140 / 90 \mathrm{mmHg}$ ) and 12 of these were under treatment with ACE inhibitors $(n=6)$, angiotensin receptor inhibitors and calcium channel antagonists $(n=2)$, or calcium channel antagonists alone $(n=3)$. One patient was treated with a low dose of hydrochlorothiazide in addition to ACE inhibitors.

Assuming the presence of anaemia for $\mathrm{Hb} \leq 11.5 \mathrm{~g} / \mathrm{dl}$ in women and $\leq 12 \mathrm{~g} / \mathrm{dl}$ in men, we used as control group for haematological parameters 42 non-anaemic subjects ( 23 males 
and 19 females, mean age 44.4 years, range $17-64$ years, $\mathrm{Hb}$ $14.01 \mathrm{mg} / \mathrm{dl}$, range $11.7-16.5 \mathrm{mg} / \mathrm{dl})$.

\section{Statistical analysis}

Data are expressed as mean \pm SD. Unpaired Student's $t$-test was used as test of significance for means in the case of variables showing normal distribution, and the $\chi^{2}$ test was used for categorical variables. The Mann-Whitney $U$-test was used for EPO and UAE values that did not satisfy the assumption of a normal distribution. Linear regression analysis was used to relate different variables. Logarithmic transformation was applied to UAE (decimal logarithm) and EPO (natural logarithm), nonparametric variables, before using linear regression analysis. Multiple linear regression analyses were performed to determine the relative contribution to the variability of $\mathrm{Hb}$ and $\mathrm{Ht}$ of different independent variables. The relationship between EPO and $\mathrm{Hb}$ was assessed by regression of $\ln \mathrm{EPO}$ on $\mathrm{Hb}$. The slopes of the regression lines obtained in the control group and in Type 2 diabetic patients were compared using $t$-test. All statistical analyses were done using the program StatView IV (SAS Institute Inc., Cary, NC, USA). A value of $2 P<0.05$ was considered significant.

\section{Results}

\section{Autonomic neuropathy assessment}

Among those with Type 2 diabetes 24 had AN and 40 did not. There were no differences between Type 2 patients with and without AN in clinical parameters, apart from the presence of a slightly higher serum creatinine level, largely in the normal range $(67.2 \pm 15.03 \mu \mathrm{mol} / \mathrm{l})$, and a higher percentage of retinopathy in the group with AN (Table 1). Three subjects, all in the group with $\mathrm{AN}$, had abnormal values of postural hypotension ( $\geq 30 \mathrm{mmHg}$ ), five patients, including one without $\mathrm{AN}$

Table 1 Clinical parameters of Type 2 diabetic patients with and without autonomic neuropathy (AN)

\begin{tabular}{lcc}
\hline Type 2 diabetic patients & Without AN & With AN \\
\hline$n$ & 40 & 24 \\
Sex $(\mathrm{M}: \mathrm{F})$ & $25: 15$ & $15: 9$ \\
Age (years) & $51.3 \pm 10.7$ & $53.4 \pm 9.4$ \\
Duration (years) & $10.1 \pm 8.9$ & $10.4 \pm 8.4$ \\
Body mass index $\left(\mathrm{kg} / \mathrm{m}^{2}\right)$ & $27.8 \pm 3.6$ & $26.9 \pm 4.2$ \\
$\mathrm{HbA}_{1 \mathrm{c}}(\%)$ & $7.5 \pm 1.4$ & $8.2 \pm 2.2$ \\
Creatinine $(\mu \mathrm{mol} / \mathrm{l})$ & $59.2 \pm 10.6$ & $67.2 \pm 15.03 *$ \\
Retinopathy $(\mathrm{no} / \mathrm{BG} / \mathrm{PR})$ & $31 / 8 / 1$ & $10 / 12 / 2 \dagger$ \\
Microalbuminuria $(\mathrm{normo} / \mathrm{micro})$ & $32 / 8$ & $19 / 5$ \\
Hypertension $(\mathrm{no} / \mathrm{yes})$ & $28 / 12$ & $21 / 3$ \\
Smokers $($ no/yes $)$ & $25 / 15$ & $17 / 7$ \\
Casual systolic BP $(\mathrm{mmHg})$ & $130.9 \pm 16.3$ & $125.5 \pm 13.4$ \\
Casual diastolic $\mathrm{BP}(\mathrm{mmHg})$ & $77.8 \pm 12.3$ & $75.9 \pm 7.8$ \\
\hline
\end{tabular}

Data are mean \pm SD.

" $t$-Test $P<0.05$.

$\dagger \chi^{2}$ test $P<0.05$.
Table 2 Day and night values and $\Delta$ day-night of blood pressure (BP) and urinary albumin excretion (UAE) in Type 2 diabetic patients with and without autonomic neuropathy (AN)

\begin{tabular}{lcc}
\hline Type 2 diabetic patients & Without AN & With AN \\
\hline$n$ & 40 & 24 \\
Day systolic BP $(\mathrm{mmHg})$ & $129.2 \pm 13.9$ & $122.9 \pm 10.0$ \\
Night systolic BP $(\mathrm{mmHg})$ & $116.5 \pm 14.9$ & $118.8 \pm 13.2$ \\
$\Delta$ day-night systolic BP $(\%)$ & $9.9 \pm 6.3$ & $3.0 \pm 11.6^{*}$ \\
Day diastolic BP $(\mathrm{mmHg})$ & $79.5 \pm 9.4$ & $76.4 \pm 6.3$ \\
Night diastolic BP $(\mathrm{mmHg})$ & $66.3 \pm 9.5$ & $69.8 \pm 9.3$ \\
$\Delta$ day-night diastolic BP $(\%)$ & $16.2 \pm 8.1$ & $8.6 \pm 10.1 *$ \\
Day UAE $(\mu \mathrm{g} / \mathrm{min})$ & $4.47(0.33-137.5)$ & $4.75(0.24-117.3)$ \\
Night UAE $(\mu \mathrm{g} / \mathrm{min})$ & $2.28(0.08-231.4)$ & $6.92(0.21-51.7)$ \\
$\Delta$ day-night UAE $(\%)$ & $11.1 \pm 112.4$ & $-35.8 \pm 135.9 \dagger$ \\
\hline
\end{tabular}

Data are mean $\pm \mathrm{SD}$, or median (range).

" $t$-Test $P<0.01$.

†Mann-Whitney test $P<0.05$.

(who was taking diuretics), showed borderline values (between 20 and $30 \mathrm{mmHg}$ ).

\section{BP monitoring and urinary measurement}

ABPM displayed lower values of $\Delta$ day-night in systolic and diastolic BP in Type 2 diabetic patients with AN than in those without AN (Table 2). No differences were observed between the two groups for day, night, and 24-h UAE, but a lower $\Delta$ daynight in UAE was present in the patients with AN (Table 2).

\section{Haematological evaluation}

When comparing diabetic individuals with and without AN, no differences were present for any haematological parameter, and values were within the normal range (Table 3). Defining anaemia as $\mathrm{Hb} \leq 11.5 \mathrm{~g} / \mathrm{dl}$ in women and $\leq 12 \mathrm{~g} / \mathrm{dl}$ in men, we did not find any anaemia in diabetic patients, but 11 out of 64 had $\mathrm{Hb}<13 \mathrm{~g} / \mathrm{dl}$. Comparison between individuals with $\mathrm{Hb}$ $>13 \mathrm{~g} / \mathrm{dl}$ and those with $\mathrm{Hb}<13 \mathrm{~g} / \mathrm{dl}$ (Table 4) showed significant differences in BMI, in ferritin and in ESR. Interestingly, all the cardiovascular tests and autonomic score were lower in those with $\mathrm{Hb}<13 \mathrm{~g} / \mathrm{dl}$. The presence of $\mathrm{Hb}<13 \mathrm{~g} / \mathrm{dl}$ was associated with female gender $\left(\chi^{2}=11.1, P<0.001\right)$, with the presence of $\mathrm{AN}\left(\chi^{2}=3.9, P<0.05\right)$ and postural hypotension $\left(\chi^{2}=7.8, P<0.05\right)$. The presence of $\mathrm{Hb}>13 \mathrm{~g} / \mathrm{dl}$ was associated with the status of actual smoker $\left(\chi^{2}=4.2, P<0.05\right)$ (Table 4$)$. Moreover, patients with $\mathrm{Hb}<13 \mathrm{~g} / \mathrm{dl}$ displayed lower $\Delta$ day-night in diastolic BP compared with those with $\mathrm{Hb}$ $>13 \mathrm{~g} / \mathrm{dl}(7.9 \pm 12.4$ vs. $14.7 \pm 8.6 \%, P<0.05)$.

\section{Relationship between autonomic function and haematological parameters}

Using simple linear regression, haematocrit was related to postural hypotension $(r=-0.30, P<0.01)$, deep breathing 
Table 3 Haematological parameters of Type 2 diabetic patients with and without autonomic neuropathy (AN)
Table 4 Clinical parameters of Type 2 diabetic patients with haemoglobin $(\mathrm{Hb})>13 \mathrm{~g} / \mathrm{dl}$ and $<13 \mathrm{~g} / \mathrm{dl}$

\begin{tabular}{lccc}
\hline Type 2 diabetic patients & Without AN & With AN & Normal values \\
\hline$n$ & 40 & 24 & - \\
Haemoglobin $(\mathrm{g} / \mathrm{dl})$ & $14.6 \pm 1.3$ & $14.1 \pm 1.6$ & $12-16$ \\
Haematocrit $(\%)$ & $43.2 \pm 4.0$ & $41.4 \pm 4.1$ & $37-47$ \\
Mean corpuscolar volume $(\mathrm{fl})$ & $89.2 \pm 4.1$ & $88.0 \pm 3.3$ & $80-99$ \\
Mean corpuscular Hb $(\mathrm{pg})$ & $29.9 \pm 1.9$ & $30.3 \pm 1.7$ & $27-31$ \\
Iron $(\mu \mathrm{mol} / \mathrm{l})$ & $14.9 \pm 4.5$ & $15.5 \pm 5.3$ & $11.6-30.4$ \\
Ferritin $(\mu \mathrm{g} / \mathrm{l})$ & $167.2 \pm 149.1$ & $175.8 \pm 166.6$ & $15-300$ \\
$\mathrm{~B}_{12}(\mathrm{pmol} / \mathrm{l})$ & $327.8 \pm 125.3$ & $427.5 \pm 291.3$ & $116-781$ \\
Folate $(\mathrm{nmol} / \mathrm{l})$ & $14.3 \pm 5.4$ & $16.1 \pm 5.9$ & $12-32.2$ \\
Erythropoietin $(\mathrm{mIU} / \mathrm{ml})$ & $7.3 \pm 4.0$ & $7.2 \pm 3.9$ & $3.3-16.6$ \\
\hline
\end{tabular}

Data are mean \pm SD.

\begin{tabular}{|c|c|c|}
\hline Type 2 diabetic patients with & $\mathrm{Hb}>13 \mathrm{~g} / \mathrm{dl}$ & $\mathrm{Hb}<13 \mathrm{~g} / \mathrm{dl}$ \\
\hline$n$ & 53 & 11 \\
\hline $\mathrm{M}: \mathrm{F}$ & $38: 15$ & $2: 9+† \dagger$ \\
\hline Age (years) & $51.6 \pm 10.6$ & $54.6 \pm 8.1$ \\
\hline Duration (years) & $10.2 \pm 8.7$ & $10.3 \pm 8.8$ \\
\hline Body mass index $\left(\mathrm{kg} / \mathrm{m}^{2}\right)$ & $28.2 \pm 3.5$ & $24.4 \pm 3.9^{* *}$ \\
\hline $\mathrm{HbA}_{1 \mathrm{c}}(\%)$ & $7.9 \pm 1.8$ & $6.9 \pm 1.2$ \\
\hline Creatinine $(\mu \mathrm{mol} / \mathrm{l})$ & $63.6 \pm 12.4$ & $55.7 \pm 14.1$ \\
\hline Erythrocyte sedimentation rate $(\mathrm{mm} / \mathrm{h})$ & $15.3 \pm 10.9$ & $32.9 \pm 19.9 * * *$ \\
\hline Retinopathy (no/BG/PR) & $37 / 14 / 2$ & $4 / 6 / 1 \dagger$ \\
\hline Microalbuminuria (normo/micro) & $41 / 12$ & $10 / 1$ \\
\hline Hypertension (no/yes) & $39 / 14$ & $10 / 1$ \\
\hline Smokers (no/yes) & $31 / 22$ & $10 / 1 \dagger$ \\
\hline Autonomic neuropathy (no/yes) & $36 / 17$ & $7 / 4+$ \\
\hline Postural hypotension (no/border/yes) & $49 / 2 / 2$ & $7 / 3 / 1 \dagger$ \\
\hline Deep breathing (bpm) & $20.4 \pm 11.9$ & $10.3 \pm 5.9^{* *}$ \\
\hline Lying to standing & $1.20 \pm 0.18$ & $1.05 \pm 0.11 * *$ \\
\hline Valsalva ratio & $1.51 \pm 0.27$ & $1.27 \pm 0.24^{*}$ \\
\hline Postural hypotension $(\mathrm{mmHg})$ & $3.43 \pm 10.9$ & $14.03 \pm 23.56^{*}$ \\
\hline Autonomic score & $1.4 \pm 2.2$ & $3.8 \pm 2.9 * *$ \\
\hline UAE $24 \mathrm{~h}(\mu \mathrm{g} / \mathrm{min})$ & $4.1(0.3-135.2)$ & $4.3(0.5-165.7)$ \\
\hline Iron $(\mu \mathrm{mol} / \mathrm{l})$ & $15.43 \pm 4.92$ & $13.88 \pm 4.14$ \\
\hline Ferritin $(\mu \mathrm{g} / \mathrm{l})$ & $187.8 \pm 161.5$ & $78.9 \pm 48.8^{*}$ \\
\hline $\mathrm{B}_{12}(\mathrm{pmol} / \mathrm{l})$ & $359.9 \pm 202.9$ & $360.3 \pm 173.4$ \\
\hline Folate $(\mathrm{nmol} / \mathrm{l})$ & $14.5 \pm 5.2$ & $16.9 \pm 7.02$ \\
\hline Erythropoietin (mIU/ml) & $7.03 \pm 3.64$ & $8.23 \pm 5.26$ \\
\hline
\end{tabular}

Data are mean \pm SD or median (range).

$t$-Test $* P<0.05 ; * * P<0.01 ; * * P<0.0001$.

$\chi^{2}$ test $+P<0.05$; †† $P<0.001$. $(r=0.25, P<0.05)$, and autonomic score $(r=-0.32, P<0.01)$. To investigate the independent effects of $\mathrm{AN}$ on haematocrit, we performed a multiple regression analysis adjusting for the other variables associated to $\mathrm{Hb}$ or related in simple regression analysis to haematocrit, i.e. gender, BMI, duration of diabetes, smoking, serum creatinine, 24-h UAE, 24-h diastolic BP, serum ferritin, and ESR (Table 5). With this model, that explained $58 \%$ of the variability of haematocrit (adjusted $R^{2}=0.58$ ), we found that autonomic score was independently related together with ESR and ferritin. Using the same model, we found that serum ferritin, ESR, and female gender were the only variables related to $\mathrm{Hb}$ (Table 5 ). Haematocrit was also related in simple regression analysis to $\Delta$ day-night in systolic $(r=0.30, P<0.01)$ and diastolic BP, but the significance of the relationship disappeared after adjusting in multiple regression analysis for autonomic score and creatinine.

\section{Relationship between $\mathrm{Hb}$ and EPO}

Using linear regression analysis, we found a significant relationship between $\ln \mathrm{EPO}$ and $\mathrm{Hb}$ in the control group of non-anaemic subjects $[t=-2.40$, degree of freedom $=40$, 


\begin{tabular}{|c|c|c|c|c|}
\hline \multirow{2}{*}{$\begin{array}{l}\text { Adjusted } R^{2} \\
F \text {-value } \\
\text { Variable }\end{array}$} & \multicolumn{2}{|l|}{$\begin{array}{l}\mathrm{Hb} \\
0.62 \\
10.13\end{array}$} & \multicolumn{2}{|l|}{$\begin{array}{l}\mathrm{Ht} \\
0.58 \\
8.95\end{array}$} \\
\hline & Coefficient & $P$-value & Coefficient & $P$-value \\
\hline Gender $($ male $=0$, female $=1)$ & -0.69 & 0.054 & -1.97 & 0.058 \\
\hline Body mass index $\left(\mathrm{kg} / \mathrm{m}^{2}\right)$ & 0.05 & 0.17 & 0.096 & 0.31 \\
\hline Duration (years) & 0.01 & 0.66 & -0.0002 & 0.99 \\
\hline Smokers $($ no $=0$, yes $=1)$ & 0.34 & 0.25 & 0.82 & 0.35 \\
\hline Autonomic score & -0.08 & 0.12 & -0.40 & 0.011 \\
\hline Creatinine $(\mu \mathrm{mol} / \mathrm{l})$ & 0.58 & 0.58 & 3.49 & 0.26 \\
\hline 24-h diastolic BP (mmHg) & 0.003 & 0.85 & 0.02 & 0.70 \\
\hline $\log 24$-h urinary albumin excretion & 0.08 & 0.68 & -0.27 & 0.64 \\
\hline Erythrocyte sedimentation rate $(\mathrm{mm} / \mathrm{h})$ & -0.03 & 0.009 & -0.073 & 0.012 \\
\hline Ferritin $(\mu \mathrm{g} / \mathrm{l})$ & 0.003 & 0.001 & 0.007 & 0.012 \\
\hline
\end{tabular}

Table 5 Multiple linear regression analysis to investigate the effects of autonomic neuropathy (autonomic score) on haemoglobin ( $\mathrm{Hb}$ ) and haematocrit (Ht) in 64 Type 2 diabetic patients, after adjusting for other variables: adjusted $R^{2}$, $F$-value, and regression coefficients $\square \quad$ Control subjects $(r=-0.36, P=0.02)$

- Type 2 patients $(r=-0.04, P=0.72)$

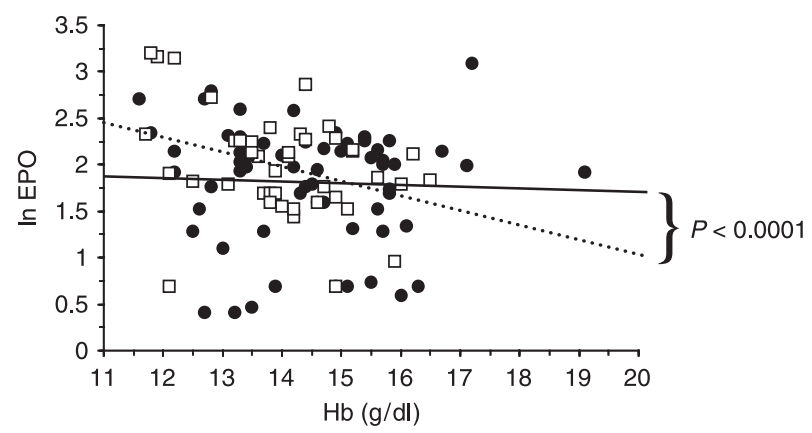

Figure 1 Relationship between the natural logarithm (ln) of serum erythropoietin (EPO) and haemoglobin $(\mathrm{Hb})$ concentrations in 64 Type 2 diabetic patients $(-)$ and in 42 non-diabetic non-anaemic control subjects $(\square)$. The slopes of the regression lines between $\ln$ EPO and haemoglobin of the control subjects (dotted line) and the Type 2 diabetic patients (solid line) were significantly different between them $(P<0.0001)$. No relationship was present at all in Type 2 diabetic patients.

$P=0.021 ; 95 \%$ confidence interval (CI) for slope -0.30 , $-0.02]$. In contrast, no relationship was observed between $\ln \mathrm{EPO}$ and $\mathrm{Hb}$ in Type 2 diabetic patients $(t=-0.36$, degree of freedom $=62, P=0.721 ; 95 \%$ CI for slope $-0.13,0.09$ ). We compared the slopes of the regression lines between $\ln \mathrm{EPO}$ and $\mathrm{Hb}$ of the control and Type 2 diabetic subjects, -0.16 and -0.02 , respectively, and found a significant difference between them $(t=14.4$, degree of freedom $=102, P<0.0001)$ (Fig. 1). Moreover, EPO levels were no higher in diabetic patients with $\mathrm{Hb}<13 \mathrm{~g} / \mathrm{dl}$ than in those with $\mathrm{Hb}>13 \mathrm{~g} / \mathrm{dl}$ (Table 4).

The six patients using ACE inhibitors did not show any significant difference in haematological parameters compared with the others.

\section{Discussion}

This study demonstrates an independent link between AN and haematological parameters in Type 2 diabetes before the development of overt nephropathy. Although Type 2 diabetic patients with $\mathrm{AN}$ did not have reduced $\mathrm{Hb}$ and EPO levels, when dividing Type 2 diabetic patients according to $\mathrm{Hb}$ levels in two groups with $\mathrm{Hb}>13 \mathrm{~g} / \mathrm{dl}$ or $<13 \mathrm{~g} / \mathrm{dl}$, we observed in the group with lower $\mathrm{Hb}$ a greater prevalence of $\mathrm{AN}$ and a greater impairment in all cardiovascular tests. Furthermore, in multiple regression analysis only the autonomic score in addition to ESR and ferritin was independently related to haematocrit.

Type 2 diabetic patients with AN displayed the expected abnormalities in circadian rhythms of BP and albumin excretion, i.e. an impaired nocturnal fall [24-26]. Haematocrit was related in univariate analysis to day-night change in BP. However, this did not persist after adjusting for autonomic score, suggesting that the link was mediated by AN. The association observed between diabetic retinopathy and AN has been attributed to the coexistence of late diabetes complications $[27,28]$.

We appear to be the first to report in patients without overt nephropathy the loss of the physiological inverse relationship between EPO levels and $\mathrm{Hb}$ concentration. This has previously been reported, but at an advanced stage of nephropathy in patients with both proteinuria and severe autonomic impairment $[13,14,29]$. In the present study, the expected association between lower $\mathrm{Hb}(<13 \mathrm{~g} / \mathrm{dl})$ and higher EPO levels was not present in the Type 2 diabetic group. Thus, this study points to a dysregulation of EPO production in Type 2 diabetes at an early stage of diabetic nephropathy before macroalbuminuria develops and renal function begins to decline.

Two recent studies in Type 1 diabetes have suggested that $\mathrm{AN}$, when associated with proteinuria, acts as a promoter of EPO-deficient anaemia [29,30]. Our study suggests that nephropathy is also not the only cause of EPO dysregulation in Type 2 diabetes. Given the specific features of diabetic nephropathy in Type 2 diabetes [19], it is possible that tubulointerstitial lesions may contribute to impaired EPO production.

Despite the exclusion of patients with active foot ulcers or known infectious diseases, we found an independent relationship between ESR and $\mathrm{Hb}$ or Ht levels. This finding suggests an 
inhibitory role for inflammatory cytokines in EPO production [31]. This is the first direct evidence of a link between haematological parameters and ESR.

The presence in multivariate analysis of a positive correlation between ferritin and $\mathrm{Hb}$ or $\mathrm{Ht}$ indicates the importance of iron stores in the maintenance of $\mathrm{Hb}$ [32], although all patients had a normochromic normocytic blood profile with normal serum ferritin level.

A limitation of this study was the absence of overtly anaemic diabetic patients, in which an EPO deficit would have been more striking. This absence was probably due to the exclusion of individuals with macroalbuminuria, in which the prevalence of anaemia increases significantly [32]. At the stage of overt nephropathy the common coexistence of AN makes it difficult to separate the respective roles of AN and nephropathy on $\mathrm{Hb}$ and EPO levels. Notwithstanding the lack of anaemic patients, the loss of the physiological relationship between EPO and $\mathrm{Hb}$ levels points to abnormal EPO regulation developing before clinical nephropathy and the appearance of anaemia. The independent relationship in the whole Type 2 diabetic group between $\mathrm{Ht}$ and autonomic score supports a contributory role of the autonomic nervous system in the maintenance of haematological homeostasis and EPO regulation.

In conclusion, this study documents an early dysregulation of EPO production with the loss of the physiological relationship between $\mathrm{Hb}$ and EPO levels before the development of overt nephropathy in Type 2 diabetes. The significant association between $\mathrm{Hb}$ and $\mathrm{AN}$ points to a role of $\mathrm{AN}$ in early $\mathrm{EPO}$ dysregulation.

\section{Acknowledgements}

Part of the study was presented at the 36th Annual Meeting of the European Association for the Study of Diabetes, Jerusalem, 17-21 September 2001 and published as an abstract form (Diabetologia 2001; 43 (Suppl. 1): A250).

\section{References}

1 Erslev AJN. Erythropoietin. N Engl J Med 1991; 324: 13391344.

2 Jelkmann W. Erythropoietin. structure, control of production, and function. Physiol Rev 1992; 72: 449-489.

3 Bachmann S, Le Hir M, Eckardt KU. Co-localization of erythropoietin mRNA and ecto-5'-nucleotidase immunoreactivity in peritubular cells of rat renal cortex indicates that fibroblasts produce erythropoietin. J Histochem Cytochem 1993; 41: 335-341.

4 Eckardt K-U. Pathophysiology of renal anemia. Clin Nephrol 2000; 53: S2-S8.

5 DiBona GF, Wilcox CS. The kidney and the sympathetic nervous system. In Mathias CJ, Bannister R eds. Autonomic Failure, 4th edn. Oxford: Oxford University Press, 1999; 18: 143-150.

6 Fink GD, Fisher JW. Erythropoietin production after renal denervation or beta-adrenergic blockade. Am J Physiol 1976; 230: 508513.

7 Beynon G. The influence of the autonomic nervous system in the control of erythropoietin secretion in the hypoxic rat. J Physiol Lond 1977; 266: 347-360.
8 Biaggioni I, Robertson D, Krantz S, Jones M, Haile V. The anemia of primary autonomic failure and its reversal with recombinant erythropoietin. Ann Intern Med 1994; 121: 181-186.

9 Perera R, Isola L, Kaufmann H. Effect of recombinant erythropoietin on anemia and orthostatic hypotension in primary autonomic failure. Clin Auton Res 1995; 5: 211-214.

10 Ando Y, Asahara K, Obayashi K, Suhr O, Yonemitsu M, Yamashita $\mathrm{T}$ et al. Autonomic dysfunction and anemia in neurologic disorders. J Auton Nerv Syst 1996; 61: 145-148.

11 Watkins PJ, Winkler AS, Marsden J, Chauduri KR. Erythropoietin responsive anaemia in diabetic autonomic neuropathy with and without nephropathy. Diabetologia 1998; 41: A309.

12 Ricerca BM, Todaro L, Caputo S, Cotroneo P, Damiani P, Manto A et al. Blunted erythropoietin response to anemia in type 1 diabetic patients. Diabetes Care 1999; 22: 647 (Letter).

13 Winkler AS, Marsden J, Chaudhurit KR, Hambley H, Watkins PJ. Erythopoietin depletion and anemia in diabetes mellitus. Diabet Med 1999; 16: 813-819.

14 Cotroneo P, Ricerca BM, Todaro L, Pitocco D, Manto A, Ruotolo V et al. Blunted erythopoietin response to anaemia in patients with type 1 diabetes. Diabetes Metab Res Rev 2000; 16: 172-176.

15 Grzeszczak W, Franek E, Kokot F. Erythropoietin level in the blood of patients with diabetes mellitus type 2. Pol Arch Med Wewn 1992; 88: 18-24.

16 Kojima K, Totsuka Y. Anemia due to reduced serum erythropoietin concentration in non-uremic diabetic patients. Diab Res Clin Pract 1995; 27: 229-233.

17 Inomata S, Itoh M, Imai H, Sato T. Serum level of erythropoietin as a novel marker reflecting the severity of diabetic nephropathy. Nephron 1997; 75: 426-430.

18 Yun YS, Lee HC, Yoo NC, Song YD, Lim SK, Kim KR et al. Reduced erythropoietin responsiveness to anemia in diabetic patients before advanced diabetic nephropathy. Diab Res Clin Pract 1999; 46: 223 229.

19 Dalla Vestra M, Saller A, Bortoloso E, Mauer M, Fioretto P. Structural involvement in type 1 and type 2 diabetic nephropathy. Diabetes Metab 2000; 26: 8-14.

20 Ewing DJ. Analysis of heart rate variability and other non-invasive tests with special reference to diabetes mellitus. In Bannister R, Mathias CJ eds. Autonomic Failure, 3rd edn. Oxford: Oxford University Press, 1992; 16: 312-333.

21 Cardone C. I test che valutano la risposta riflessa cardiovascolare. Neuropatia Diabetica: Rassegna Bibliografica 1990; 2: 151160.

22 Bellavere F, Bosello G, Fedele D, Cardone C, Ferri M. Diagnosis and management of diabetic autonomic neuropathy. $\mathrm{Br}$ Med J 1983; 287: 61 (Letter)

23 O'Brien E, Mee F, Atkins N, O'Malley K. Evaluation of the SpaceLabs 90202 non-invasive ambulatory recorder according to the AAMI Standard and BHS criteria. J Hum Hypertens 1991; 5: 223226.

24 Winocour PH, Hanka D, Andersen DC. The relationship between autonomic neuropathy and urinary sodium and albumin excretion in insulin-treated diabetics. Diabet Med 1986; 3: 436-440.

25 Spallone V, Gambardella S, Maiello MR, Barini A, Frontoni S, Menzinger G. Relationship between autonomic neuropathy, 24-h blood pressure profile and nephropathy in normotensive IDDM patients. Diabetes Care 1994; 17: 578-584.

26 Spallone V, Maiello MR, Cicconetti E, Pannone A, Barini A, Gambardella $S$ et al. Factors determining the 24 -h blood pressure profile in normotensive patients with type 1 and type 2 diabetes. J Hum Hypertens 2001; 15: 239-246.

27 Krolewski AS, Barzilay J, Warram JH, Martin BC, Pfeifer M, Rand LI. Risk of early-onset proliferative retinopathy in IDDM is closely related to cardiovascular autonomic neuropathy. Diabetes 1992; 41: 430-437. 
28 Poulsen PL, Bek T, Ebbehoj E, Hansen KW, Mogensen CE. 24-h ambulatory blood pressure and retinopathy in normoalbuminuric IDDM patients. Diabetologia 1998; 41: 105110.

29 Bosman DR, Winkler AS, Marsden JT, Macdougall IC, Watkins PJ. Anemia with erythropoietin deficiency occurs early in diabetic nephropathy. Diabetes Care 2001; 24: 495-499.

30 Bosman DR, Osborne CA, Marsden JT, Macdougall IC, Gardner WN,
Watkins PJ. Erythropoietin response to hypoxia in patients with diabetic autonomic neuropathy and non-diabetic chronic renal failure. Diabet Med 2002; 19: 65-69.

31 Means RT. Advances in the anemia of chronic disease. Int J Hematol 1999; 70: 7-12.

32 Thomas MC, MacIsaac RJ, Tsalamandris C, Power D, Jerums G. Unrecognized anemia in patients with diabetes. Diabetes Care 2003; 26: $1164-1169$. 